Preprint

UCRL-JC-149106

\title{
Interferometric Diagnosis of Two-Dimensional Plasma Expansion
}

\author{
R. F. Smith, S. Moon, J. Dunn, J. Nilsen, V. N. Shlyaptsev, \\ J. R. Hunter, J. Rocca, J. Filevich, M. C. Marconi
}

This article was submitted to

$8^{\text {th }}$ International Conference on X-ray Lasers, Aspen, CO., May 2731,2002

July 31, 2002

Lawrence

Livermore

National

Laboratory

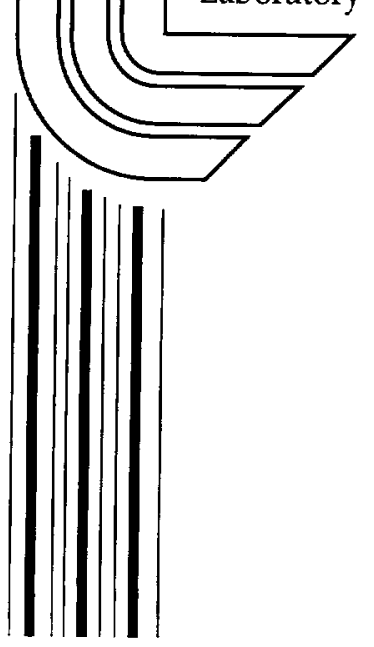




\section{DISCLAIMER}

This document was prepared as an account of work sponsored by an agency of the United States Government. Neither the United States Government nor the University of California nor any of their employees, makes any warranty, express or implied, or assumes any legal liability or responsibility for the accuracy, completeness, or usefulness of any information, apparatus, product, or process disclosed, or represents that its use would not infringe privately owned rights. Reference herein to any specific commercial product, process, or service by trade name, trademark, manufacturer, or otherwise, does not necessarily constitute or imply its endorsement, recommendation, or favoring by the United States Government or the University of California. The views and opinions of authors expressed herein do not necessarily state or reflect those of the United States Government or the University of California, and shall not be used for advertising or product endorsement purposes.

This is a preprint of a paper intended for publication in a journal or proceedings. Since changes may be made before publication, this preprint is made available with the understanding that it will not be cited or reproduced without the permission of the author.

This work was performed under the auspices of the United States Department of Energy by the University of California, Lawrence Livermore National Laboratory under contract No. W-7405-Eng-48.

This report has been reproduced directly from the best available copy.

Available electronically at http://www.doc.gov/bridge

Available for a processing fee to U.S. Department of Energy

And its contractors in paper from

U.S. Department of Energy

Office of Scientific and Technical Information

P.O. Box 62

Oak Ridge, TN 37831-0062

Telephone: (865) 576-8401

Facsimile: (865) 576-5728

E-mail: reports@adonis.osti.gov

Available for the sale to the public from

U.S. Department of Commerce

National Technical Information Service

5285 Port Royal Road

Springfield, VA 22161

Telephone: (800) 553-6847

Facsimile: (703) 605-6900

E-mail: orders@ntis.fedworld.gov

Online ordering: http://www.ntis.gov/ordering.htm

\section{OR}

Lawrence Livermore National Laboratory

Technical Information Department's Digital Library

http://www.llnl.gov/tid/Library.html 


\title{
Interferometric Diagnosis of Two-Dimensional Plasma Expansion
}

\author{
Raymond F. Smith ${ }^{1}$, Steven Moon ${ }^{1}$, James Dunn ${ }^{1}$, Joseph Nilsen ${ }^{1}$, \\ Vyacheslev N. Shlyaptsev ${ }^{1}$, James R. Hunter ${ }^{1}$, Jorge Rocca ${ }^{3}$, \\ Jorge Filevich ${ }^{3}$, Mario C. Marconi, ${ }^{3,4}$ \\ ${ }^{I}$ Lawrence Livermore National Laboratory, Livermore, CA 94551 \\ ${ }^{2}$ University of California Davis-Livermore, Livermore, CA 94551 \\ ${ }^{3}$ Dept. of Electrical and Computer Engineering, Colorado State University, \\ Fort Collins, CO 80523 \\ ${ }^{4}$ Physics Dept., University of Buenos Aires, Argentina
}

\begin{abstract}
Recent advances in interferometry has allowed for the characterization of the electron density expansion within a laser produced plasma to within $10 \mu \mathrm{m}$ of the target surface and over picosecond timescales. This technique employs the high brightness output of the transient gain Nilike Pd collisional $\mathrm{x}$-ray laser at $14: \mathrm{nm}$ to construct an effective moving picture of the twodimensional (2-D) expansion within the plasma. In this paper"we present experimentally measured density profiles from an $\mathrm{Al}$ plasma and make comparisons with 1.5-D and 2-D code simulations. The results are discussed along with an analysis of the underlying mechanisms driving the plasma expansion.
\end{abstract}

\section{INTRODUCTION}

Interferometry is a powerful tool for accurately diagnosing the two-dimensional (2-D) evolution of dense laser-produced plasmas. For fast evolving plasmas it is desirable that the duration of the probe pulse is short to obtain an effective snapshot of the density profile while reducing the effects of plasma motion blurring at the ablation front. The picosecond duration and short wavelength of the $14.7 \mathrm{~nm} \mathrm{Ni-like} \mathrm{Pd} \mathrm{laser}$ mitigates effects associated with motion blurring and refraction through millimeter scale plasmas. This enables direct measurement of the electron density profile to within $10 \mu \mathrm{m}$ of the target surface [1]. A series of high quality 2-D density measurements provide unambiguous characterization of the time evolution in a fast evolving plasma suitable for validation of existing 1-D and 2-D hydrodynamic codes. The electron density evolution of a laser-heated Al plasma is measured using a diffraction grating interferometer (DGI) [2] at different times, relative to the peak of the plasma forming pulse. The experimental results are compared with 1.5-D and 2-D hydrodynamic simulations in order to further our understanding of the mechanisms driving plasma expansion. 


\section{EXPERIMENTAL RESULTS}

The Ni-like Pd $14.7 \mathrm{~nm}$ x-ray laser probe beam and the plasma to be studied were generated using three laser beams at $1054 \mathrm{~nm}$ wavelength from the COMET facility at LLNL [1]. Single pass saturated x-ray laser output of a few 10 's of $\mu \mathrm{Js}$ was achieved with an optical pumping combination of a 600 ps long pulse $\left(2 \mathrm{~J}, 2 \times 10^{11} \mathrm{~W} \mathrm{~cm}^{-2}\right)$ and a 6 ps $\left(5 \mathrm{~J}, 7 \times 10^{13} \mathrm{~W} \mathrm{~cm}^{-2}\right)$ main heating pulse. The $\mathrm{x}$-ray laser output was imaged and routed into a diffraction grating interferometer for plasma probing experiments. For details of the instrumentation see ref $[1,2]$.

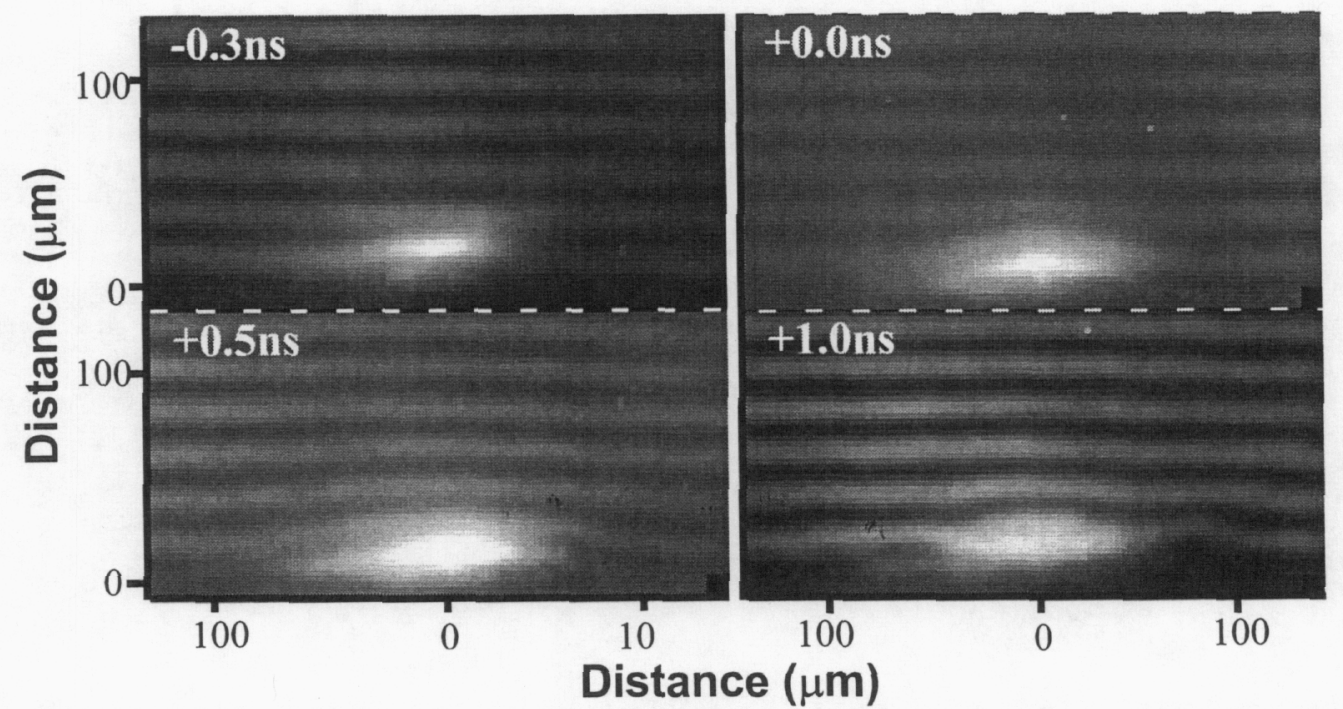

Figure 1. Interferograms representing 2-D electron density profiles for different times relative to the peak of the 600 ps plasma forming pulse.

A plasma heated by up to $2 \mathrm{~J}$ of energy in a $600 \mathrm{ps}, 1054 \mathrm{~nm}$ pulse, corresponding to a maximum intensity of $3 \times 10^{12} \mathrm{~W} \mathrm{~cm}^{-2}$, was produced in one arm of the interferometer. A $6 \mathrm{~mm}$ long line focus with a $20 \mu \mathrm{m}$ focal width, was generated on a polished $1 \mathrm{~mm}$ long Al slab target using a combination of a cylindrical lens, $f=-200$ $\mathrm{cm}$, and an off-axis paraboloid, $f=30 \mathrm{~cm}$. The relative delay between the arrival of the $\mathrm{x}$-ray laser probe pulse, represented by the short pulse beam, to the peak of the plasma forming beam was measured to within $100 \mathrm{ps}$ with a fast diode. The $\mathrm{x}$-ray laser could probe the plasma in the temporal range of $-1 \mathrm{~ns}$ to $+2 \mathrm{~ns}$ relative to the peak of the 600 ps plasma forming pulse by adjusting a delay arm in the plasma laser beam. The line focus plasma was probed longitudinally by the x-ray laser, thereby minimizing uncertainties in the interpretation of the interferograms arising from plasma gradients along the probe path. The plasma was imaged by a $25 \mathrm{~cm}$ focal length spherical multilayer mirror and relayed to a thinned back-illuminated $1024 \times 1024 \mathrm{CCD}$ detector with $24 \times 24 \mu \mathrm{m}^{2}$ pixels. A $2000 \AA \mathrm{Zr} / 1000 \AA$ Polyimide $\left(\mathrm{C}_{22} \mathrm{H}_{10} \mathrm{~N}_{2} \mathrm{O}_{5}\right)$ filter was placed in front of the CCD to block visible and UV light. The magnification of the imaging system was determined to be 9.94 , by imaging a fine mesh at the target plane, 
giving a pixel-limited spatial resolution of $2.55 \mu \mathrm{m}$. The target angle was determined to be parallel to the $\mathrm{x}$-ray laser beam to better than $\pm 0.25^{\circ}$. Using the $\mathrm{x}$-ray laser beam with no plasma present, high quality fringes, with visibility $V=\left(I_{\max }-I_{\min }\right) /\left(I_{\max }+I_{\min }\right)$ of $0.72 \pm 0.12$, were observed for a $700 \times 500 \mu \mathrm{m}^{2}(\mathrm{H} \times \mathrm{V})$ region indicating excellent spatial coherence in the laser beam. Figure 1 shows a series of interferograms at different probing times relative to the peak of the plasma forming pulse. The electron density, $\mathrm{n}_{\mathrm{e}}$ in $\mathrm{cm}^{-3}$, is related to the measured fringe shifts as $N_{\text {fringe }}=6.68 \times 10^{-20} n_{e} L$, where $\mathrm{L}$ is the length $(\mathrm{cm})$ of the plasma being probed by the $14.7 \mathrm{~nm}$ x-ray laser [3].

Significant lateral expansion from the initial $20 \mu \mathrm{m}$ focal width is observed at all times with the expansion velocity parallel to the target surface measured to be $7.5 \times 10^{6} \mathrm{~cm} / \mathrm{s}$ over the interval of probing. This is in agreement with the expected sound speed for a plasma electron temperature of $T_{e} \sim 80 \mathrm{eV}$. For all the interferograms the sideways expansion is symmetrical about the center of the focusing region. A lot of structure is observed less than $10 \mu \mathrm{m}$ from the target surface at the limit of the spatial resolution of the imaging system. At $1 \mathrm{~ns}$ after the peak of the plasma forming pulse we observed off-axis density enhanced lobes close to the target surface and at approximately $80 \mu \mathrm{m}$ either side of the central region. In addition, perturbations in the fringes away from the target surface indicated an expansion angle of $\pm 35^{\circ}$ at $\mathrm{t}>0.5 \mathrm{~ns}$.

\section{SIMULATIONS}

Figure 2(a) shows the experimentally observed on-axis electron density profile for different probing times. It can be seen at early times, $\mathrm{t}=-0.3 \mathrm{~ns}$ and $0 \mathrm{~ns}$, that the density scale-length is short and the plasma has expanded to $60 \mu \mathrm{m}$ from the initial target surface. At later times, $\mathrm{t}=+0.7 \mathrm{~ns}$ and $1.0 \mathrm{~ns}$ when the plasma heating pulse is effectively off, the plasma scale-length has relaxed and the plasma has continued to expand to $160 \mu \mathrm{m}$. Analysis considering the effects of refraction [4] has shown a 20\% uncertainty in the highest density measurements. The lowest measured electron density for this target length is limited to $2 \times 10^{18} \mathrm{~cm}^{-3}$ and is dependent on the minimum detection of the fringe shift. The error bars on the density measurement in Figure 2(a) represent the uncertainty in determining the position of the fringes.

Alongside these measurements are the predicted electron density values from the 1.5-D LASNEX [5] plasma physics code. The LASNEX simulations are onedimensional but include an expansion angle of 15 degrees in the direction perpendicular to the primary expansion (1.5-D) so as to simulate the 2-D effects associated with the narrow width of the line focus on the target. The code predictions give qualitatively good agreement in reproducing the plasma density profile evolution. The overall trend, however, is for the simulations to show somewhat higher density at all times. The predicted $n_{e}$ values increase rapidly within $5 \mu \mathrm{m}$ of the target surface. Experimental images indicate very fine fringe structure in this region, which are not well resolved by our present imaging setup. Within our current experimental setup, this has proved to be the limit on the maximum diagnosable electron density. This however does not represent the limit of the technique. The critical density for the 14.7 
$\mathrm{nm}$ probe wavelength is $5 \times 10^{24} \mathrm{~cm}^{-3}$ and gives the ultimate limit to the density with which the $\mathrm{x}$-ray laser can probe. By optimizing the instrumentation and plasma conditions we expect to closer approach this figure in future experimental work.
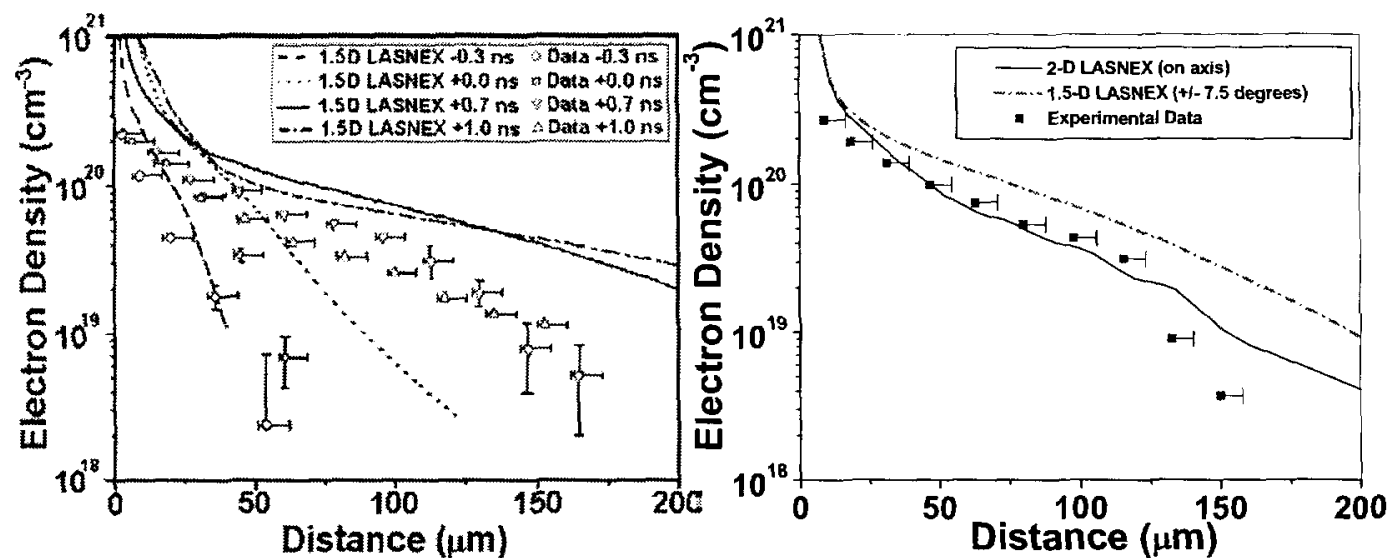

Figure 2 (a) 1-D on axis density slices from experimentally obtained interferograms compared with profiles predicted by 1.5-D LASNEX simulations. (b) Comparison of on axis density from 2-D and 1.5-D $\left( \pm 7.5^{\circ}\right)$ LASNEX simulations with experimentally obtained electron density measurements at $t=0.5$ ns.

Figure 2(b) shows the experimentally determined electron density as a function of distance away from the target surface taken 0.5 ns after the peak of the plasma forming pulse. Also shown is the predicted on axis electron density from the LASNEX 1.5-D $\left( \pm 7.5^{\circ}\right)$ and 2-D simulations. It is clear that there is better agreement for the latter. For the 1.5-D case, all the ablated mass is artificially confined to a fixed cone angle of expansion, an approximation which, in the case of significant lateral expansion, will increase the predicted on-axis density. It has been found that by increasing the cone angle within the 1.5-D simulations improved agreement with experiment is obtained.
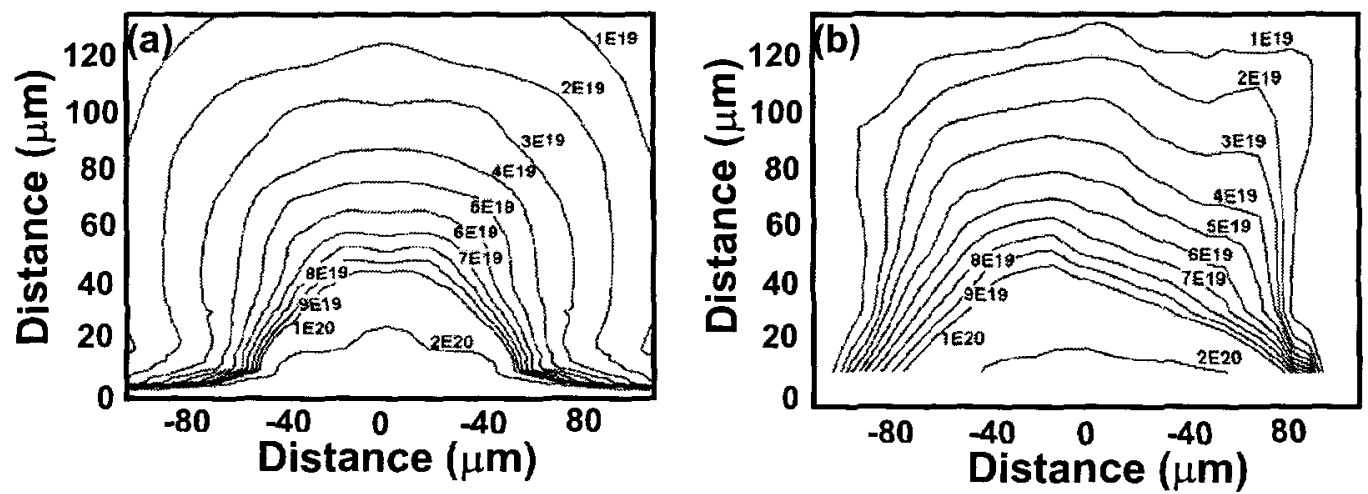

Figure 3 (a) Simulated 2-D electron density profile using LASNEX. (b) Measured 2-D electron density profile $0.5 \mathrm{~ns}$ after the peak of the $600 \mathrm{ps}$ duration plasma forming beam. The error bars for distance away from the target are $-2 \mu \mathrm{m},+8 \mu \mathrm{m}$.

Figure 3 shows a contour plot of a 2-D LASNEX [4] simulation and the 
corresponding experimental data at $\Delta t=0.5 \mathrm{~ns}$ with good quantitative agreement. Such modeling covers all phases of expansion leading to a plasma size much larger than the focal spot. To understand the mechanisms driving the expansion of the plasma it is necessary to track the evolution of the plasma parameters. Figure 4(a) shows the calculated 2-D electron temperature and density profile at the peak of the $600 \mathrm{ps}$ plasma forming beam. It is predicted that there exists a hot $(\sim 150 \mathrm{eV})$ on-axis region close to the critical surface of the $1 \omega$ driver. The temperature gradients relax slowly in the plane of primary expansion. However there are steep gradients in the lateral direction. The plasma close to the target is calculated to be relatively cold $(\sim 40 \mathrm{eV})$ just outside the $20 \mu \mathrm{m}$ FWHM of the laser driver. An electron density contour map is also shown on the same plot. It is seen that at the peak of the pulse a rippling of the critical density surface is predicted, with side lobes developing at low temperatures at approximately $20 \mu \mathrm{m}$ off-axis. In figure 4(b) a momentum vector map illustrates that there is a significant lateral push of mass from these side lobe regions in the direction away from the center of the focusing beam.
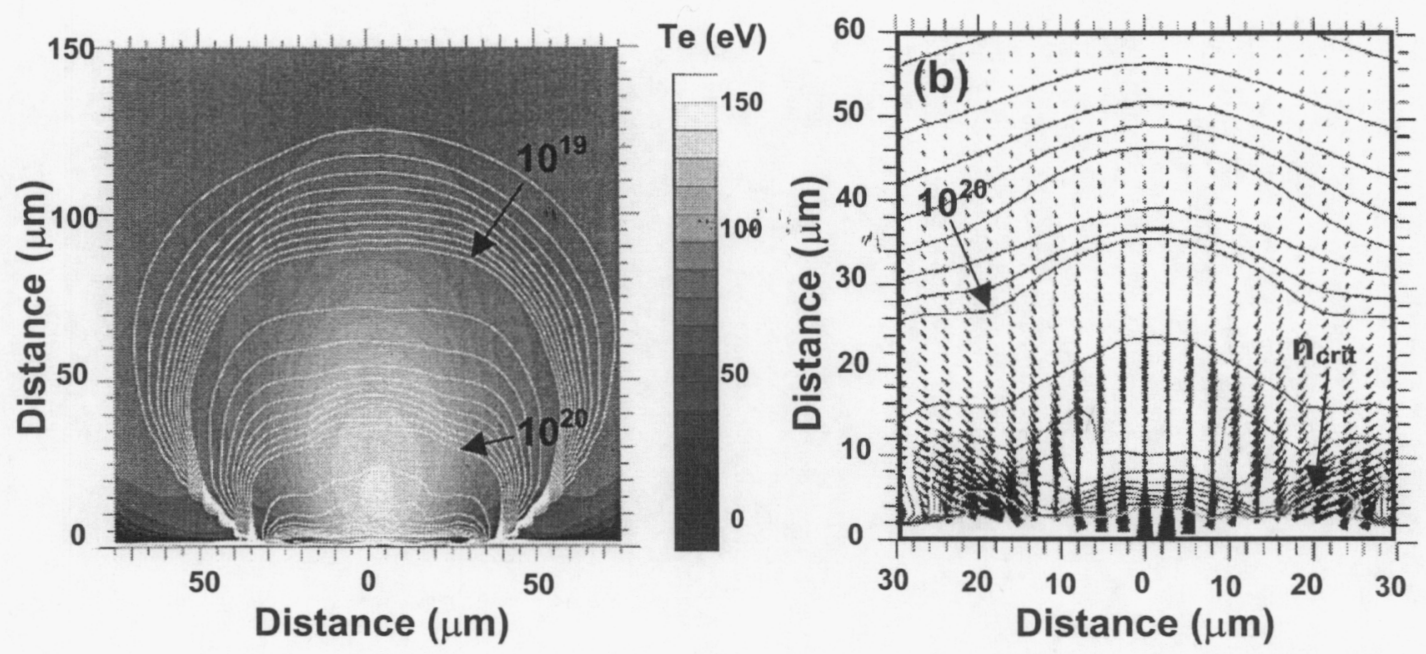

Figure 4 (a) Electron density and electron temperature contours at the peak of the plasma forming pulse $[\Delta \mathrm{t}=0 \mathrm{~ns}]$ (b) Momentum vector plot at the same time.

\section{CONCLUSIONS}

Picosecond $\mathrm{x}$-ray laser interferometry is a valuable technique in diagnosing plasma evolution within laser produced plasmas. The short sampling time of the probe beam reduces blurring effects and allows for probing to within $10 \mu \mathrm{m}$ of the target surface. In addition, the short wavelength probe minimizes effects associated with refraction and free-free absorption making this diagnostic well suited for studying large, fast evolving, dense plasmas. It has been shown that for the experimental conditions reported within this paper lateral expansion is a significant effect. Two-dimensional plasma physics codes are therefore necessary to model such experiments. Preliminary 
simulations have indicated that cool dense and relatively slow moving regions, which lie outside of the full width at half maximum (FWHM) of the laser focus, drive the lateral expansion. Future work will focus on understanding the dominant energy transport mechanisms, which drive the plasma expansion.

\section{ACKNOWLEDGEMENTS}

The support of Al Osterheld and Andy Hazi is greatly appreciated. The authors are pleased to acknowledge the technical contributions from Carl Bruns and Al Ellis. This work was performed under the auspices of the U.S. Dept. of Energy by the University of California Lawrence Livermore National Laboratory, through the Institute for Laser Science and Applications, under Contract No. W-7405-Eng-48 and by US Department of Energy Grant No. DE-FG03-98DP00208. The development of the interferometer gratings was supported with a grant from the State of Colorado Photonics and Optoelectronics program.

\section{REFERENCES}

1. R.F. Smith, J.Dunn, J. Nilsen, V.N. Shlyaptsev, S. Moon, J. Filevich, J.J. Rocca, M.C. Marconi, J.R. Hunter, and T.W. Barbee, Jr., Phys. Rev. Lett., 89 (6), 065004-1 (2002).

2. J. Filevich, K. Kanizay, M. C. Marconi, J. L. A. Chilla, ánd J. J. Rocca, Opt. Lett. 25, 356-357 (2000).

3. L. B. Da Silva, T. W. Barbee, Jr., R. Cauble, P. Celliers, D. Ciarlo, S. Libby, R. A. London, D. Matthews, S. Mrowka, J. C. Moreno, D. Ress, J. E. Trebes, A. S. Wan, and F. Weber, Phys. Rev. Lett. 74, 3991-3994 (1995).

4. R.F. Smith, V.N. Shlyaptsev, J. Dunn, J. Nilsen, J.R. Hunter, J.J. Rocca and J. Filevich, M.C. Marconi, "Refraction Effects on X-ray and UV Interferometric Probing of Laser Produced Plasmas" submitted for publication to JOSAB (2002).

5. G.B Zimmerman and W.L. Kruer, Comments Plasma Phys. Controlled Fusion 2, 51-61 (1975). 